\title{
Comparação de métodos para dimensionamento de reservatórios de água pluvial
}

\author{
Comparison of methods for rainwater tank sizing
}

\author{
Ricardo Forgiarini Rupp \\ Ulisses Munarim \\ Enedir Ghisi
}

\section{Resumo}

Ricardo Formagiarini Rupp Laboratório de Eficiência Energética em Edificações, Departamento de Engenharia Civil

Universidade Federal de Santa Catarina Florianópolis - SC - Brasil Caixa Postal 476 CEP 88040-900

Tel.: (48) 3721-5185 E-mail: ricardorupp@gmail.com

Ulisses Munarim Laboratório de Eficiência Energética em Edificações, Departamento de

Engenharia Civi

Universidade Federal de Santa Catarina

E-mail: ulisses@labeee.ufsc.br

Enedir Ghisi Laboratório de Eficiência Energética em Edificações, Departamento de Engenharia Civi Universidade Federal de Santa Catarina E-mail: enedir@labeee.ufsc.br

Recebido em 16/05/11

Aceito em 06/09/11

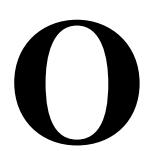

objetivo deste artigo é comparar com o programa computacional objetivo deste artigo é comparar com o programa computacional Netuno os diversos métodos para o dimensionamento do reservatório de água pluvial sugeridos na norma brasileira NBR 15527. Foram calculados os volumes de reservatório para residências em três cidades no Brasil, Santos, Palhoça e Santana do Ipanema, escolhidas por apresentarem características distintas de precipitação. Na aplicação dos métodos, variou-se a área de captação, a demanda de água potável e a demanda de água pluvial, o que resultou em diversos casos analisados. Os mesmos casos foram simulados no Netuno, que fornece os potenciais de economia de água potável para cada volume de reservatório. Os volumes de reservatório obtidos por meio dos outros métodos também foram simulados no Netuno para se obterem os respectivos potenciais de economia de água potável. Dessa forma, foi possível comparar a capacidade dos reservatórios, o potencial de economia de água potável obtido com cada método e a aplicabilidade de cada um dos métodos para diferentes condições de precipitação. Observou-se que alguns métodos não são adequados para algumas condições de precipitação, pois resultam sempre no mesmo volume de reservatório, independentemente da demanda de água pluvial ou do regime de precipitação, podendo levar à instalação de reservatórios subdimensionado ou superdimensionados. Com o Netuno, foi possível dimensionar o reservatório para todas as situações simuladas. Trata-se do único método cujo dimensionamento ajustou-se de modo mais racional quando comparado aos demais métodos da NBR 15527, em função da demanda de água pluvial de todos os casos e dos regimes de precipitação.

Palavras-chave: Aproveitamento de água pluvial. Dimensionamento de reservatório de água pluvial. Métodos de dimensionamento.

\section{Abstract}

The objective of this paper is to compare the various methods of rainwater tank sizing suggested in the Brazilian standard NBR 15527 with the Neptune computer programme. The rainwater tank capacities were estimated for homes in three cities in Brazil: Santos, Palhoça and Santana do Ipanema, chosen due to their different rainfall patterns. Different roof areas, potable water demands, and rainwater demands were analysed using each method. The same cases were simulated in Neptune, which provides the potential potable water savings for each tank capacity. The tank capacities obtained by the other methods were also simulated in Neptune in order to obtain their respective potentials for potable water savings. Thus, it was possible to compare the rainwater tank capacities, the potential for potable water savings obtained with each method, and the applicability of each method for different rainfall patterns. The results showed that some methods are not suitable for certain rainfall patterns, since they always provide the same tank capacity, regardless of rainwater demand or rainfall; and this may result in under- or oversized tanks. By contrast, using Neptune, it was possible to size the tanks for all the simulated cases; and it was the only method whose tank sizing provided more reliable results when compared to other NBR 15527 methods, due to the rainwater demand in all cases and rainfall patterns.

Keywords: Rainwater harvesting. Rainwater tank sizing. Sizing methods. 


\section{Introdução}

É praticamente consenso na comunidade científica internacional que o problema da depleção das fontes de água para consumo humano está chegando a uma condição preocupante. Devido ao crescimento populacional, muitas regiões, tais como norte da África, parte dos Estados Unidos, países do Oriente Médio, China, Índia, México, Tailândia e, inclusive, parte do Brasil, já retiram mais água do lençol freático do que a quantidade capaz de ser reposta pelo ciclo hidrológico. Heine et al. (2005) apontam para um desequilíbrio entre a exploração e a recarga natural do Sistema Aquífero Guarani, manancial presente em oito estados brasileiros, que atende ao abastecimento de boa parte de seus territórios. Segundo dados do Programa Ambiental das Nações Unidas (UNITED..., 2002), em 1950 havia $80.000 \mathrm{~m}^{3} /$ ano de água doce disponível por pessoa para uma população mundial de 2,5 bilhões de habitantes. Em 2050 esse volume de água cairá para 23.000 $\mathrm{m}^{3} /$ ano por pessoa se a população aumentar para 9 bilhões de pessoas, como se prevê.

O uso doméstico de água em edificações contribui em grande monta para o agravamento desse problema. Na América do Sul, o consumo de água em edificações responde por $18 \%$ do total de água doce utilizada; no Brasil, a parcela é de 16\%. Uma alternativa viável para reduzir a escassez de água em muitas regiões é realizar a captação de água pluvial para sua utilização nas edificações (HELMREICH; HORN, 2009).

O dimensionamento da capacidade do reservatório para armazenamento de água pluvial é um dos pontos críticos na implantação do sistema, pois:

(a) geralmente, é um dos itens mais caros na implantação do sistema, impactando significativamente o tempo de retorno do investimento; e

(b) é o principal fator a influenciar na confiabilidade do sistema, ou seja, desempenha um papel importante em evitar ocorrências em que a quantidade de água no reservatório é insuficiente para atender à demanda.

Portanto, o correto dimensionamento do reservatório é importante para evitar gastos desnecessários quando o reservatório é superdimensionado; ou baixa eficiência, quando o reservatório é subdimensionado. Segundo Ghisi (2010), o dimensionamento do reservatório de água pluvial para residências deve ser específico para cada situação, e não baseado na tradição local.

Estudos que tratam de métodos para o dimensionamento de reservatório para o armazenamento de água pluvial já foram apresentados por Villarreal e Dixon (2005), Fewkes (1999), Appan (1999), Zhang et al. (2009) e Eroksuz e Rahman (2010). Outros autores (GHISI; BRESSAN; MARTINI, 2007; KHASTAGIR; JAYASURIYA，2010; GHISI, 2010) focaram-se em encontrar volumes ótimos de reservatório de água pluvial. Uma recente pesquisa americana (BASINGER; MONTALTO; LALL, 2010) fez uma análise sobre a precisão de vários métodos empregados no dimensionamento do reservatório de água pluvial. Porém, o estudo foi feito com base na literatura, sem aplicar os métodos em testes e comparar os resultados. Os autores apontam que a confiabilidade dos métodos de dimensionamento de reservatório de água pluvial depende, sobretudo, do tipo de dados de precipitação utilizados. Basinger, Montalto e Lall (2010) sugerem a utilização de séries sintéticas de precipitação criadas a partir de processos estocásticos não paramétricos. Dessa forma, o algoritmo de simulação de série de precipitação pode processar qualquer série histórica, não se limitando à precipitação de uma localidade em específico.

No Brasil, Carvalho, Oliveira e Moruzzi (2007) realizaram estudo comparando o dimensionamento de reservatórios de água pluvial, para atender à demanda de bacia sanitária de uma residência unifamiliar na cidade de Rio Claro (SP), pelo método do Máximo Aproveitamento - proposto por Mierzwa et al. (2007) - e pelo método da Análise da Simulação. O método do Máximo Aproveitamento oferece a possibilidade de analisar graficamente o volume anual aproveitável de água pluvial em função de diferentes volumes de reservatório. Já o método da Análise da Simulação permite determinar a eficiência do sistema para cada volume de reservatório. Segundo os autores, um método ideal reuniria essas particularidades dos dois métodos analisados.

Outro estudo comparativo entre os métodos de dimensionamento utilizados no Brasil foi empreendido por Amorim e Pereira (2008a, 2008b). No entanto, a pesquisa excluiu da comparação o programa computacional Netuno (GHISI; CORDOVA; ROCHA, 2009), visto que à época do estudo ele utilizava apenas os dados de precipitação pluviométrica de Florianópolis, Santa Catarina. Amorim e Pereira (2008a, 2008b) testaram os métodos para apenas uma condição de precipitação, no caso, para a cidade de São Carlos, $\mathrm{SP}$. Os autores não chegaram a indicar qual o melhor método para o dimensionamento de reservatórios de água pluvial. Concluíram que os 
métodos Azevedo Neto e Prático Inglês resultam em reservatórios superdimensionados, assim como em diversas variações nos cálculos utilizando o método de Rippl. Os métodos Prático Alemão e Prático Australiano forneceram volumes de reservatório mais conservadores. Para os autores, a opção por um método ou outro deve se dar com base nos interesses do projeto de captação de água pluvial - como, por exemplo, espaço disponível para instalação do reservatório e eficiência pretendida para o sistema - e de acordo com a região de implantação dele.

Mais recentemente, estudo comparou os métodos de dimensionamento da NBR 15527 (ABNT, 2007) com o decreto municipal de Curitiba (BEZERRA et al., 2010). Os autores chegaram à mesma conclusão de Amorim e Pereira (2008a, 2008b): ao testar a aplicação dos métodos para edifícios localizados na cidade de Curitiba/PR, os resultados discrepantes de volume de reservatório não possibilitaram determinar qual é o método mais adequado. Os autores apontam também para a dificuldade de aplicação dos métodos utilizando apenas o texto da NBR 15527 (ABNT, 2007), pois há ambiguidade e diferenças na denominação das variáveis das equações.

Os estudos citados, que compararam os métodos de dimensionamento propostos para o Brasil, tomaram como estudo de caso apenas uma localidade cada um. Dessa forma, suas conclusões a respeito do desempenho de cada método são aplicáveis apenas para um regime de precipitação específico. Nesse contexto, e visto que o Netuno já aceita dados de precipitação de qualquer região, é válido contrapor os resultados de dimensionamento apresentados pelo programa com aqueles dos demais métodos recomendados pela NBR 15527 (ABNT, 2007), considerando diferentes regimes de precipitação.

O objetivo deste artigo é comparar os métodos para o dimensionamento do reservatório de água pluvial sugeridos na NBR 15527 (ABNT, 2007) com o programa computacional Netuno, com relação à capacidade dos reservatórios, ao potencial de economia de água potável e à aplicabilidade dos métodos.

\section{Materiais e Métodos}

\section{Dados pluviométricos}

Utilizando cada um dos métodos sugeridos na NBR 15527 (ABNT, 2007) e o programa Netuno, foram calculados os volumes de reservatório para residências em três cidades no Brasil: Santos, Palhoça e Santana do Ipanema.

Essas cidades foram escolhidas por possuírem características distintas de precipitação. A cidade de Santos, localizada no Estado de São Paulo, apresenta precipitação média anual de $3.375 \mathrm{~mm}$. Sua precipitação média mensal é mostrada na Figura 1. A cidade de Palhoça, localizada no Estado de Santa Catarina, possui precipitação média anual de $1.697 \mathrm{~mm}$. Sua precipitação média mensal é apresentada na Figura 2. Já na cidade de Santana do Ipanema, localizada no sertão de Alagoas, a precipitação média anual é de $624 \mathrm{~mm}$, e sua precipitação média mensal é mostrada na Figura 3.

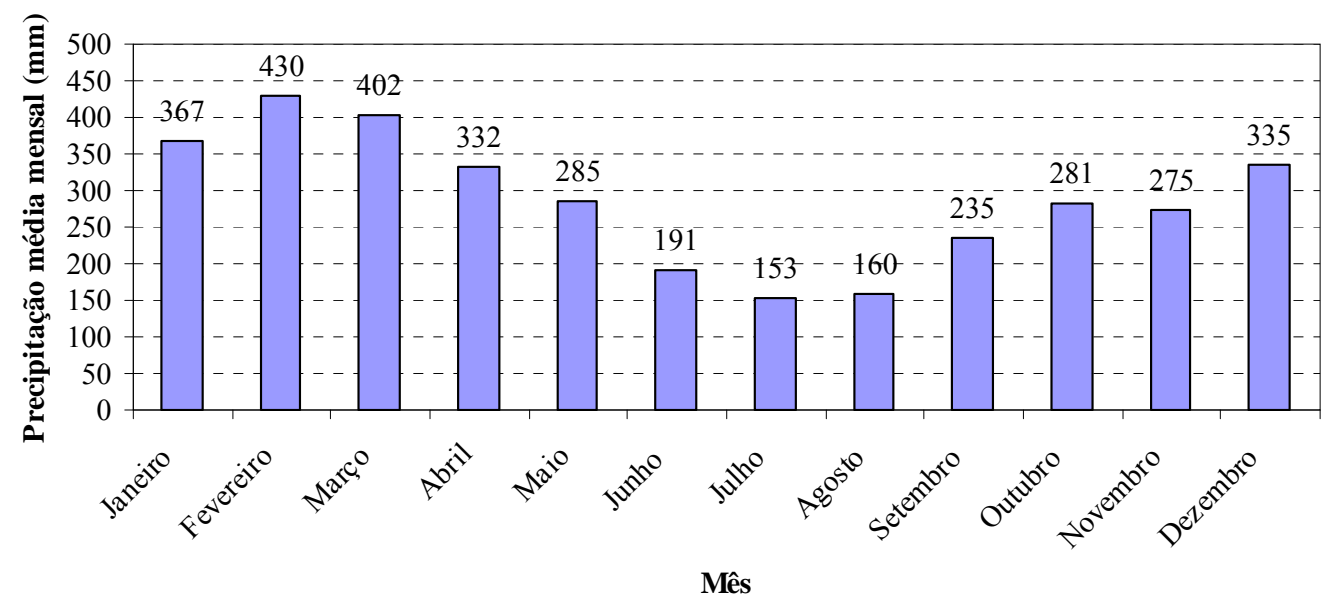

Figura 1 - Precipitação média mensal da cidade de Santos entre janeiro de 1970 e dezembro de 1999 


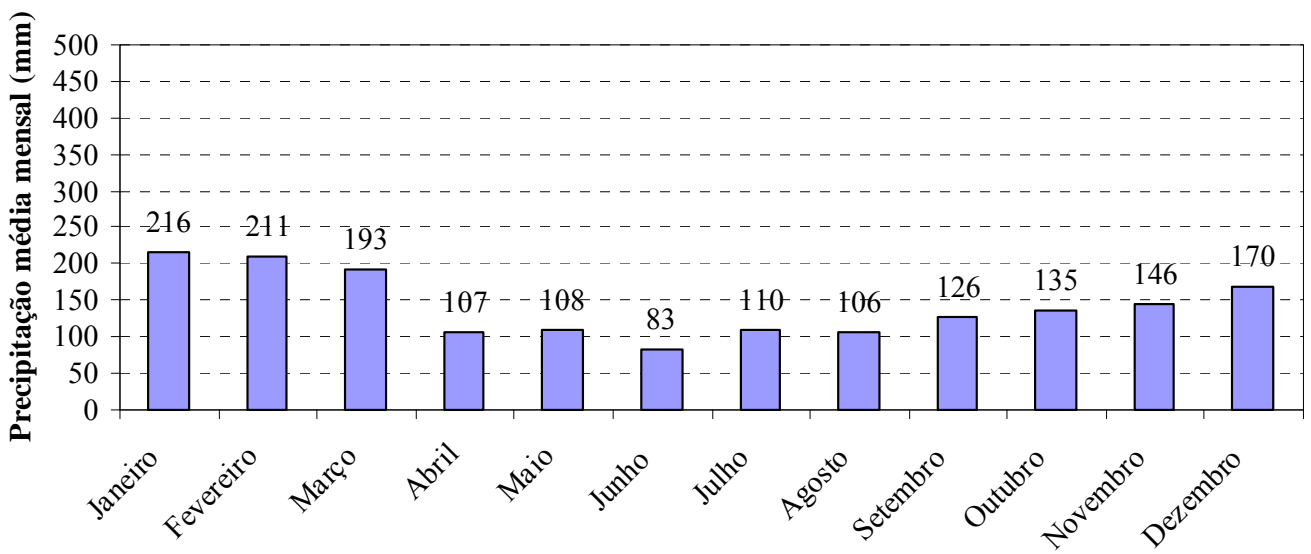

Mês

Figura 2 - Precipitação média mensal da cidade de Palhoça entre janeiro de 1970 e dezembro de 1999

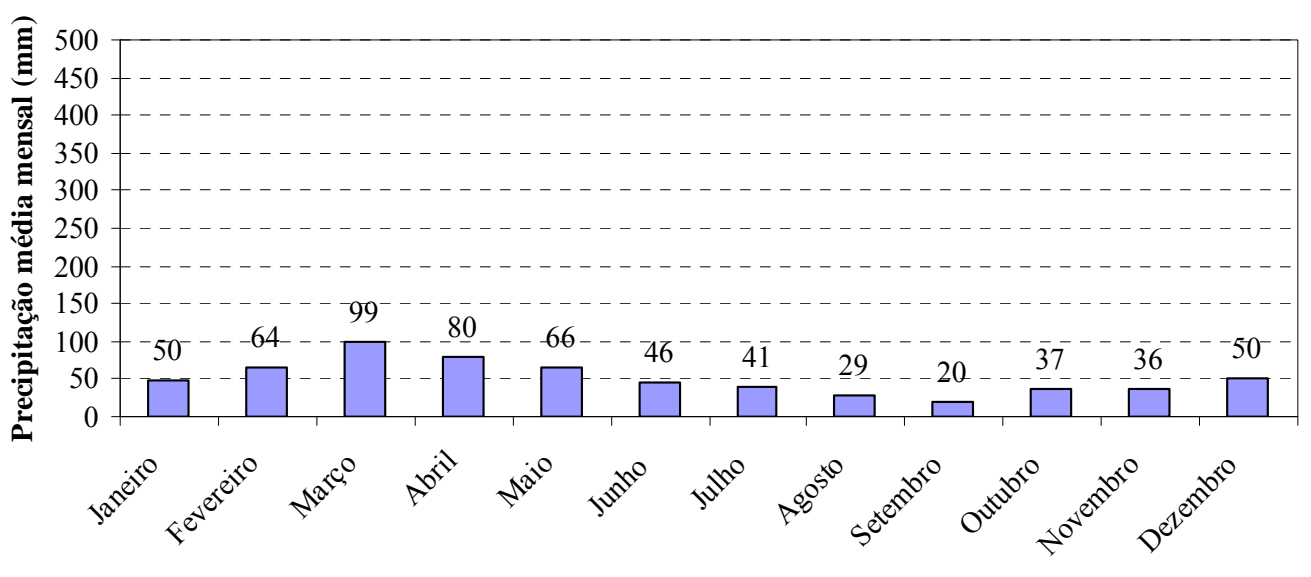

Mês

Figura 3 - Precipitação média mensal da cidade de Santana do Ipanema para um período de 30 anos

Para as cidades de Santos e Palhoça, utilizou-se uma série histórica de precipitação de 30 anos. O período considerado foi o de janeiro de 1970 a dezembro de 1999. Para a cidade de Santana do Ipanema, também foi utilizada uma série histórica de 30 anos, no entanto não havia informações disponíveis sobre as datas de início e fim do período. Para todas as cidades, quando não havia o registro da precipitação diária, ela foi adotada como sendo zero. As séries de precipitação para a cidade de Santos foram obtidas no Departamento de Águas e Energia Elétrica de São Paulo (Daee); para a cidade de Palhoça, na Empresa de Pesquisa Agropecuária e Extensão Rural de Santa Catarina (Epagri); para Santana do Ipanema, na Diretoria de Hidrometeorologia do Estado de Alagoas (DHM). Todos os dados estavam em base diária. Quando necessário, segundo os dimensionamentos usados nos diferentes métodos, esses dados foram convertidos para médias mensais ou anuais.

\section{Estudos de caso}

Por cada método e para cada cidade, os dimensionamentos dos reservatórios de água pluvial foram realizados para 27 casos diferentes, variando-se a área de captação, a demanda de água potável, a porcentagem de substituição de água potável por pluvial e, consequentemente, a demanda de água pluvial. Dessa forma, foram simuladas residências ocupadas por dois moradores e com as seguintes características:

(c) demanda diária de água potável de 100, 200 e 300 litros per capita;

(d) porcentagem de substituição de água potável por pluvial de $30 \%, 40 \%$ e $50 \%$;

(e) área de captação de 100, 200 e $300 \mathrm{~m}^{2}$; e

(f) demanda de água pluvial de 1.800, 2.400, $3.000, .3600,4.800,5.400,6.000,7.200$ e 9.000 litros/mês.

Oliveira e Ghisi (2007) estimaram o potencial de economia de água potável em duas residências 
localizadas em Palhoça/SC. Constataram que os potenciais de economia, quando se utiliza água pluvial, são da ordem de $34,5 \%$ para ambas as residências. Em estudo realizado em um conjunto de três blocos de apartamentos residenciais, Ghisi e Ferreira (2007) determinaram o percentual de substituição de água potável por água pluvial em $40,66 \%$, sendo essa a média para os três blocos de apartamentos. Desse modo, neste trabalho são utilizados percentuais de substituição de água potável por água pluvial de $30 \%, 40 \%$ e $50 \%$. As combinações entre as variações simuladas estão apresentadas na Tabela 1.

\section{Métodos de dimensionamento do reservatório de água pluvial sugeridos na NBR 15527}

A NBR 15527 (ABNT, 2007) prescreve que, na concepção do sistema de aproveitamento de água pluvial, "deve constar o alcance do projeto, a população que utiliza a água de chuva e a determinação da demanda a ser definida pelo projetista do sistema". Além desses, é imprescindível ao projetista o estudo das séries históricas e possivelmente das séries sintéticas das precipitações da região onde será feito o projeto de aproveitamento de água pluvial. A norma também define que o dimensionamento da capacidade do reservatório de água pluvial pode ser feito com qualquer método, a critério do projetista, desde que a escolha seja devidamente justificada. No entanto, seis métodos de cálculo são sugeridos no documento: método de Rippl, método da Simulação, método Azevedo Neto, método Prático Alemão, método Prático Inglês e método Prático Australiano.

A descrição detalhada de cada um desses métodos já foi feita por Amorim e Pereira (2008). Entretanto, visto que as orientações da NBR 15527 (ABNT, 2007) sobre a aplicação dos métodos são bastante sucintas, os procedimentos adotados neste artigo para realizar os dimensionamentos são detalhados a seguir.

Tabela 1 - Estudos de caso para o dimensionamento dos reservatórios

\begin{tabular}{|c|c|c|c|c|}
\hline Caso & $\begin{array}{c}\text { Área de } \\
\text { captação }\left(\mathrm{m}^{2}\right)\end{array}$ & $\begin{array}{c}\text { Demanda diária de água } \\
\text { potável (litros/per } \\
\text { capita) }\end{array}$ & $\begin{array}{c}\text { \% substituição de } \\
\text { água potável por } \\
\text { pluvial }\end{array}$ & $\begin{array}{c}\text { Demanda de água } \\
\text { pluvial (litros/mês) }\end{array}$ \\
\hline 1 & \multirow{9}{*}{100} & 100 & \multirow{3}{*}{$30 \%$} & 1.800 \\
\hline 2 & & 200 & & 3.600 \\
\hline 3 & & 300 & & 5.400 \\
\hline 4 & & 100 & \multirow{3}{*}{$40 \%$} & 2.400 \\
\hline 5 & & 200 & & 4.800 \\
\hline 6 & & 300 & & 7.200 \\
\hline 7 & & 100 & \multirow{3}{*}{$50 \%$} & 3.000 \\
\hline 8 & & 200 & & 6.000 \\
\hline 9 & & 300 & & 9.000 \\
\hline 10 & \multirow{9}{*}{200} & 100 & \multirow{3}{*}{$30 \%$} & 1.800 \\
\hline 11 & & 200 & & 3.600 \\
\hline 12 & & 300 & & 5.400 \\
\hline 13 & & 100 & \multirow{3}{*}{$40 \%$} & 2.400 \\
\hline 14 & & 200 & & 4.800 \\
\hline 15 & & 300 & & 7.200 \\
\hline 16 & & 100 & \multirow{3}{*}{$50 \%$} & 3.000 \\
\hline 17 & & 200 & & 6.000 \\
\hline 18 & & 300 & & 9.000 \\
\hline 19 & \multirow{9}{*}{300} & 100 & \multirow{3}{*}{$30 \%$} & 1.800 \\
\hline 20 & & 200 & & 3.600 \\
\hline 21 & & 300 & & 5.400 \\
\hline 22 & & 100 & \multirow{3}{*}{$40 \%$} & 2.400 \\
\hline 23 & & 200 & & 4.800 \\
\hline 24 & & 300 & & 7.200 \\
\hline 25 & & 100 & \multirow{3}{*}{$50 \%$} & 3.000 \\
\hline 26 & & 200 & & 6.000 \\
\hline 27 & & 300 & & 9.000 \\
\hline
\end{tabular}




\section{Método de Rippl}

Segundo Thomaz (2003), no método de Rippl, utilizam-se séries históricas de precipitações - as mais longas possíveis -, transformadas em vazões que alimentam o reservatório. Thomaz aponta que, de forma a facilitar o cálculo, é comum se formularem séries sintéticas, ou seja, elaboradas a partir de uma série histórica de precipitação, que pode ser em base diária ou mensal. Neste trabalho, o dimensionamento foi feito utilizando-se séries históricas de precipitação tanto em base diária quanto mensal.

Para o dimensionamento devem ser determinados a demanda média de água pluvial, a área da superfície de captação e o coeficiente de runoff (coeficiente de escoamento superficial, quociente entre a água que escoa superficialmente e o total da água precipitada), de acordo com as necessidades estabelecidas em projeto. Em seguida, aplica-se o método de Rippl utilizando-se as precipitações médias mensais em um período de janeiro a dezembro para o cálculo em base mensal. Se o objetivo for fazer o cálculo em base diária, utiliza-se uma série histórica de 10 anos de precipitações diárias. Pode ser utilizada tanto uma demanda constante de água pluvial quanto uma demanda variável. No caso deste trabalho, foi utilizada demanda constante.

O dimensionamento por esse método inicia-se pelos cálculos do volume de água pluvial no reservatório no tempo $\mathrm{t}$ e do volume de água pluvial no tempo t, expressos pelas Equações 1 e 2 respectivamente.

$\mathrm{S}_{(\mathrm{t})}=\mathrm{D}_{(\mathrm{t})}-\mathrm{Q}_{(\mathrm{t})}$

$\mathrm{Q}_{(\mathrm{t})}=\mathrm{C} \times \mathrm{P} \times \mathrm{A}$

Eq. 2

Onde:

$\mathrm{S}_{(\mathrm{t})}$ é o volume de água pluvial no reservatório no tempo $\mathrm{t}(\mathrm{L})$;

$\mathrm{D}_{(\mathrm{t})}$ é a demanda ou consumo de água pluvial no tempo $\mathrm{t}(\mathrm{L})$;

$\mathrm{Q}_{(\mathrm{t})}$ é o volume de água pluvial no tempo $\mathrm{t}(\mathrm{L})$;

C é o coeficiente de escoamento superficial (adotado como 0,80, segundo recomendações da NBR 15527 (ABNT, 2007));

$\mathrm{P}$ é a precipitação média no tempo $\mathrm{t}(\mathrm{mm})$; e

A é a área de captação em projeção no terreno $\left(\mathrm{m}^{2}\right)$.

A capacidade do reservatório de água pluvial é calculada por meio da Equação 3, mostrada abaixo.

$\mathrm{V}=\Sigma \mathrm{S}(\mathrm{t})$, somente para valores $\mathrm{S}(\mathrm{t})>0$

Eq. 3
Onde $\mathrm{V}$ é o volume do reservatório (L), sendo $\Sigma \mathrm{D}_{(\mathrm{t})}<\Sigma \mathrm{Q}_{(\mathrm{t})}$.

\section{Método da Simulação}

Esse método baseia-se na determinação do percentual de consumo que será atendido em função de um tamanho de reservatório previamente definido. Também é chamado de Método de Análise de Simulação de um Reservatório com Capacidade Suposta.

Segundo Tomaz (2003), uma característica desse método é que ele possibilita determinar a eficiência do sistema, pois os períodos em que o reservatório está suficientemente abastecido com água pluvial são relacionados com todo o período simulado. Tal período pode ser de apenas um ano, mas, quanto maior a série histórica de precipitação utilizada, maior será a confiabilidade da simulação.

A NBR 15527 (ABNT, 2007) recomenda ainda que, nesse método, a evaporação da água não seja levada em conta.

Inicia-se o dimensionamento do reservatório de água pluvial pelo método da Simulação calculando-se o volume de água pluvial no tempo $\mathrm{t}$ e o volume de água pluvial no reservatório no tempo $t$, através das Equações 4 e 5 respectivamente, que devem ser aplicadas para cada mês do ano.

$\mathrm{Q}_{(\mathrm{t})}=\mathrm{C} \times \mathrm{P} \times \mathrm{A}$

$\mathrm{S}_{(\mathrm{t})}=\mathrm{Q}_{(\mathrm{t})}+\mathrm{S}_{(\mathrm{t}-1)}-\mathrm{D}_{(\mathrm{t})}$

Eq. 5

Onde:

$\mathrm{Q}_{(\mathrm{t})}$ é o volume de água pluvial no tempo $\mathrm{t}(\mathrm{L})$;

C é o coeficiente de escoamento superficial $(0,80)$;

P é a precipitação média no tempo $\mathrm{t}(\mathrm{mm})$;

A é a área de captação em projeção no terreno $\left(\mathrm{m}^{2}\right)$;

$\mathrm{S}_{(\mathrm{t})}$ é o volume de água pluvial no reservatório no tempo t $(\mathrm{L})$;

$\mathrm{S}_{(\mathrm{t}-1)}$ é o volume de água pluvial no reservatório no tempo t-1 (L); e

$\mathrm{D}_{(\mathrm{t})}$ é o consumo ou demanda de água pluvial no tempo $\mathrm{t}(\mathrm{L})$.

$\mathrm{Na}$ sequência, determina-se um volume de reservatório $\mathrm{V}$ que atenda, para o mês de janeiro, à condição $\mathrm{V} \geq \mathrm{S}(\mathrm{t}) \geq 0$. Se essa condição for atendida ao longo dos demais 11 meses do ano, esse volume $\mathrm{V}$ é o volume do reservatório. Caso contrário, deve-se determinar outro volume de reservatório $\mathrm{V}$ até que se atenda à condição $\mathrm{V} \geq$ $\mathrm{S}(\mathrm{t}) \geq 0$ para os 12 meses do ano. 
A norma alerta que devem ser consideradas duas hipóteses:

(a) reservatório cheio no tempo " $t$ "; $\mathrm{e}$

(b) os dados históricos são representativos para as condições futuras.

\section{Método Prático Brasileiro ou Método Azevedo Neto}

O método Prático Brasileiro é o primeiro método empírico apresentado na NBR 15527 (ABNT, 2007). O volume do reservatório de água pluvial é calculado por meio da Equação 6.

$\mathrm{V}=0,042 \times \mathrm{P} \times \mathrm{A} \times \mathrm{T}$

Eq. 6

Onde:

V é o volume de água no reservatório, ou o volume do reservatório de água pluvial (L);

$\mathrm{P}$ é a precipitação média anual (mm);

A é a área de captação em projeção no terreno $\left(\mathrm{m}^{2}\right) ; \mathrm{e}$

$\mathrm{T}$ é o número de meses de pouca chuva ou seca.

A NBR 15527(ABNT, 2007) não especifica como determinar o número de meses de pouca chuva. Amorim e Pereira (2008) adotaram um valor igual a 2 meses para a cidade de São Carlos/SP. Porém, os autores não mencionaram como determinaram esses meses de pouca chuva. Desse modo, neste trabalho, os meses que possuem uma precipitação igual ou inferior a $80 \%$ da precipitação média mensal foram considerados meses de pouca chuva. A Tabela 2 mostra a precipitação média mensal, a precipitação média mensal multiplicada por $80 \% \mathrm{e}$ o número de meses de pouca chuva adotado para cada cidade, bem como os valores de precipitação média anual utilizados nos cálculos de dimensionamento.

\section{Método Prático Alemão}

Neste método, o volume do reservatório de água pluvial será, simplesmente, o menor valor entre $6 \%$ do volume de água pluvial anual e $6 \%$ da demanda anual de água não potável (Equação 7).

Vadotado $=$ mínimo $\left\{\begin{array}{l}\mathrm{V} \times 0,06 \\ \mathrm{D} \times 0,06\end{array}\right.$
Onde:

V é o volume de água de pluvial anual (L);

D é a demanda anual da água não potável (L); e

$\mathrm{V}_{\text {adotado }}$ é o volume do reservatório (L).

Na NBR 15527 (ABNT, 2007) não consta como se obtém o volume de água pluvial anual pelo método Prático Alemão; portanto, ele foi determinado por meio da Eq. 2. As demandas anuais de água não potável foram obtidas através dos valores de demanda de água pluvial (Tabela 1), simplesmente multiplicando aqueles valores por 12 .

\section{Método Prático Inglês}

Para o dimensionamento do reservatório de água pluvial pelo método Prático Inglês, segundo a NBR 15527 (ABNT, 2007), deve-se utilizar a Equação 8.

$\mathrm{V}=0,05 \times \mathrm{P} \times \mathrm{A}$

Eq. 8

Onde:

V é o volume de água pluvial, ou o volume do reservatório de água pluvial (L);

$\mathrm{P}$ é a precipitação média anual (mm); e

A é a área de captação em projeção no terreno $\left(\mathrm{m}^{2}\right)$.

\section{Método Prático Australiano}

No último método sugerido pela NBR 15527 (ABNT, 2007), primeiramente se calcula o volume de água pluvial por meio da Equação 9.

$\mathrm{Q}=\mathrm{A} \times \mathrm{C} \times(\mathrm{P}-\mathrm{I})$

Eq. 9

Onde:

Q é o volume mensal de água pluvial (L);

A é a área de captação em projeção no terreno $\left(\mathrm{m}^{2}\right)$;

C é o coeficiente de escoamento superficial $(0,80)$;

$\mathrm{P}$ é a precipitação média mensal ( $\mathrm{mm})$; e

I é a interceptação da água que molha as superfícies e as perdas por evaporação (seguindo recomendação da NBR 15527 (ABNT, 2007), consideraram-se $2 \mathrm{~mm}$ ).

Tabela 2 - Precipitação média anual e número de meses de pouca chuva

\begin{tabular}{lcccc}
\hline \multicolumn{1}{c}{ Cidade } & $\begin{array}{c}\text { Precipitação média } \\
\text { anual (mm) }\end{array}$ & $\begin{array}{c}\text { Precipitação média } \\
\text { mensal (mm) }\end{array}$ & $\begin{array}{c}\text { 80\% x Precipitação média } \\
\text { mensal (mm) }\end{array}$ & $\begin{array}{c}\text { T } \\
\text { (meses) }\end{array}$ \\
\hline Santos & 3.375 & 287 & 230 & 3 \\
Palhoça & 1.697 & 143 & 114 & 5 \\
Santana do Ipanema & 624 & 52 & 41 & 5 \\
\hline
\end{tabular}


O cálculo do volume do reservatório é realizado por tentativas através da Equação 10 (onde, para o primeiro mês, considera-se o reservatório vazio), até que seja alcançado um valor dentro de um intervalo de confiança de $90 \%$ a $99 \%$.

$\mathrm{V}_{(\mathrm{t})}=\mathrm{V}_{(\mathrm{t}-1)}+\mathrm{Q}_{(\mathrm{t})}-\mathrm{D}_{(\mathrm{t})}$

Onde:

$\mathrm{V}_{(\mathrm{t})}$ é o volume de água pluvial que está no reservatório no fim do mês $\mathrm{t}(\mathrm{L})$;

$\mathrm{V}_{(\mathrm{t}-1)}$ é o volume de água pluvial que está no reservatório no início do mês t $(\mathrm{L})$;

$\mathrm{Q}_{(\mathrm{t})}$ é o volume de água pluvial no mês $\mathrm{t}(\mathrm{L})$; e

$\mathrm{D}_{(\mathrm{t})}$ é a demanda mensal de água não potável (L).

Quando $\left(\mathrm{V}_{(\mathrm{t}-1)}+\mathrm{Q}_{(\mathrm{t})}-\mathrm{D}_{(\mathrm{t})}\right)<0$, então o $\mathrm{V}_{(\mathrm{t})}=0$.

A confiança $\mathrm{Cf}$ é estimada por meio da Equação 11 .

$\mathrm{Cf}=1-\frac{\mathrm{N}_{(\mathrm{r})}}{\mathrm{N}}$

Eq. 11

Onde:

$\mathrm{N}_{(\mathrm{r})}$ é o número de meses em que o reservatório não atendeu à demanda; e

$\mathrm{N}$ é o número de meses considerado (geralmente 12 meses).

$\mathrm{Na}$ aplicação dos seis métodos acima explicados, as áreas de captação são dadas pela Tabela 1, e as precipitações médias mensais, pelas Figuras 1, 2 e 3 .

\section{Dimensionamento do reservatório de água pluvial utilizando-se o programa Netuno}

O Netuno, versão 3.0, é um programa computacional desenvolvido no LabEEE/UFSC (GHISI; CORDOVA; ROCHA, 2009), validado por Rocha (2009), que tem por objetivo determinar o potencial de economia de água potável em função da capacidade do reservatório, através do aproveitamento de água pluvial para usos em que a água não precisa ser potável. O programa permite que se façam simulações do potencial de economia de água potável tanto para um volume de reservatório quanto para diversos volumes, ao mesmo tempo. O programa gera gráficos que possibilitam analisar comparativamente o potencial de economia para diferentes volumes de reservatórios, facultando ao usuário escolher o volume mais adequado a suas necessidades.

Para a simulação de diversos reservatórios, o Netuno possibilita determinar o volume ideal do reservatório inferior. O critério usado para tal cálculo consiste em comparar o potencial de economia obtido para volumes de reservatórios adjacentes. Considera-se, então, como volume ideal aquele cujo acréscimo no potencial de economia do volume subsequente é igual ou inferior ao intervalo entre potenciais de economia de água potável adotado. $\mathrm{O}$ intervalo entre os potenciais de economia deve ser definido pelo usuário. Neste trabalho, o volume ideal do reservatório foi definido como aquele em que o potencial de economia de água potável aumentasse $0,5 \%$ ou menos, quando houvesse o aumento do volume do reservatório em 500 litros.

O Netuno realiza os cálculos em base diária considerando a demanda e a disponibilidade de água pluvial. Os dados de entrada são os seguintes:

(a) precipitação pluviométrica diária;

(b) área de captação;

(c) coeficiente de aproveitamento;

(d) demanda diária de água potável per capita;

(e) número de moradores; e

(f) percentagem de água potável que pode ser substituída por pluvial.

A sequência de cálculos do algoritmo do Netuno é a seguinte.

(1) Determinação do volume de água pluvial que escoa pela superfície de captação diariamente, calculado por meio da Equação 12.

$\mathrm{H}_{\mathrm{t}}=\mathrm{P} \times \mathrm{A} \times \mathrm{C}_{\mathrm{p}}$

Eq. 12

Onde:

$\mathrm{H}_{\mathrm{t}}$ é o volume de água pluvial captada no tempo $\mathrm{t}$ (litros/dia por residência);

P é a precipitação pluviométrica diária $(\mathrm{mm} /$ dia $=$ $\mathrm{L} / \mathrm{m}^{2}$ por dia);

A é a área de captação em cada residência $\left(\mathrm{m}^{2}\right)$; e

$\mathrm{C}_{\mathrm{p}}$ é o coeficiente de aproveitamento

(adimensional), adotado como 0,80.

(2) Determinação do volume de água pluvial consumido diariamente, calculado por meio da Equação 13.

$\mathrm{C}_{\mathrm{t}}=$ mínimo $\left\{\begin{array}{l}\mathrm{D}_{\mathrm{p}} \times \mathrm{D} \times \mathrm{n} \\ \mathrm{V}_{\mathrm{t}-1}+\mathrm{H}_{\mathrm{t}}\end{array}\right.$

Onde:

$\mathrm{C}_{\mathrm{t}}$ é o volume de água pluvial consumido no tempo t (litros/dia por residência); 
$\mathrm{D}_{\mathrm{p}}$ é a demanda diária de água pluvial (adimensional; \% da demanda de água potável);

D é a demanda diária de água potável (litros per capita/dia);

n é o número de moradores (adimensional);

$\mathrm{V}_{\mathrm{t}-1}$ é o volume de água pluvial disponível no reservatório no tempo t-1 (L); e

$\mathrm{H}_{\mathrm{t}}$ é o volume de água pluvial captada no tempo $\mathrm{t}$ (litros/dia por residência).

Determinação do volume de água pluvial disponível no reservatório após suprir total ou parcialmente a demanda, calculado por meio da Equação 14.

$\mathrm{Vt}=$ máximo $\left\{\begin{array}{l}0 \\ \text { Mínimo }\left\{\begin{array}{l}\mathrm{V}_{\mathrm{t}-1}+\mathrm{H}_{\mathrm{t}}=-\mathrm{C}_{\mathrm{t}} \\ \mathrm{V}-\mathrm{C}_{\mathrm{t}}\end{array}\right.\end{array}\right.$

Onde:

$\mathrm{V}_{\mathrm{t}}$ é o volume de água pluvial consumido armazenado no reservatório no tempo t (L);

$\mathrm{V}_{\mathrm{t}-1}$ é o volume de água pluvial disponível no reservatório no tempo t-1 (L);

$\mathrm{H}_{\mathrm{t}}$ é o volume de água pluvial captada no tempo $\mathrm{t}$ (litros/dia por residência);

$\mathrm{C}_{\mathrm{t}}$ é o volume de água pluvial consumido no tempo $\mathrm{t}$ (litros/dia por residência); e

V é o volume do reservatório de água pluvial (L).

(3) Determinação do potencial de economia de água potável, calculado por meio da Equação 15.

$$
E=100 \times \frac{\sum_{i=1}^{d} C_{t}}{D \times n \times d}
$$

Onde:

E é o potencial de economia de água potável estimado (\%);

$\mathrm{C}_{\mathrm{t}}$ é o volume de água pluvial consumido diariamente $(\mathrm{L})$;

D é a demanda diária de água potável (litros per capita/dia);

n é o número de moradores (adimensional); e

d é o número de dias no período analisado.

Primeiramente, foram realizadas simulações de sistemas de captação de água pluvial sem reservatório superior. Isso foi feito para permitir a comparação dos resultados do Netuno com os métodos da NBR 15527 (ABNT, 2007), visto que em nenhum dos métodos dessa norma considera-se reservatório superior. Dessa forma, foi possível comparar os potenciais de economia provenientes da aplicação dos métodos da NBR 15527 (ABNT, 2007) com as simulações realizadas no Netuno.

Em seguida, foram realizadas novas simulações no Netuno, desta vez considerando a existência de um reservatório superior. Assim, foi possível avaliar a influência que este poderia ter nos valores de potencial de economia quando comparado com o Netuno sem reservatório superior. Quando utilizado, o reservatório superior foi definido com a capacidade de 310 litros, por ser o menor reservatório encontrado no mercado, que satisfaz a demanda máxima de água potável diária, de 300 litros.

\section{Tratamento dos dados}

O Netuno, além de informar a capacidade ideal do reservatório, fornece os potenciais de economia de água potável para cada volume de reservatório. Assim, os resultados obtidos pelos outros métodos também foram simulados no Netuno, para se chegar a seus respectivos potenciais de economia. Dessa forma, os resultados buscados expressam:

(a) as capacidades dos reservatórios obtidas para cada uma das áreas de captação e calculadas por meio de cada método, em função das demandas de água pluvial; e

(b) os potenciais de economia de água potável para cada capacidade de reservatório.

Os resultados foram analisados com relação às variações dos dados de entrada e de precipitações em cada um dos métodos. Em seguida, as capacidades de reservatório e o potencial de economia de água potável obtidos por cada método foram comparados entre si.

Os valores de demanda de água pluvial (L/mês) e de potencial de economia (\%) foram convertidos para $\mathrm{L} / \mathrm{m}^{2}$ de área de captação. Essa conversão foi realizada dividindo-se os valores de demanda e de potencial de economia pelas áreas de captação de cada caso.

A possibilidade de se utilizar cada um dos métodos para dimensionar o reservatório de água pluvial, ou seja, de fornecer um volume de reservatório como resultado a partir dos dados de entrada em cada caso simulado, foi o que determinou sua aplicabilidade ou não para as condições de precipitação analisadas. 
A comparação entre os volumes de reservatório obtidos pela aplicação de cada método entre os sugeridos na NBR 15527 (ABNT, 2007) com o volume ideal obtido no programa Netuno permitiu determinar se os métodos superdimensionam ou subdimensionam os reservatórios.

\section{Resultados}

Nesta seção apresentam-se os resultados dos dimensionamentos dos reservatórios de água pluvial calculados pelos diferentes métodos apresentados na NBR 15527 (ABNT, 2007), bem como seus respectivos potenciais de economia de água potável. Também são apresentados os resultados dos dimensionamentos realizados no Netuno, com e sem reservatório superior. Os resultados dos dimensionamentos pelo método de Rippl, em base diária, foram desconsiderados, pois os volumes de reservatório calculados superaram muito os dos demais métodos.

\section{Capacidades dos reservatórios e potenciais de economia de água potável}

Os resultados dos dimensionamentos dos reservatórios para a cidade de Santos encontram-se na Tabela 3. Como se pode perceber, não foi possível dimensionar os reservatórios pelos métodos de Rippl, da Simulação e Prático Australiano para nenhuma das demandas de água pluvial e áreas de captação.

A Tabela 4 expressa os resultados dos dimensionamentos dos reservatórios para a cidade de Palhoça. Somente foi possível dimensionar os reservatórios pelo método de Rippl e da Simulação, para as demandas de água pluvial mais elevadas e com área de captação de $100 \mathrm{~m}^{2}$. Já pelo método Prático Australiano, foi possível dimensionar os reservatórios para as demandas de água pluvial mais elevadas e com área de captação de $300 \mathrm{~m}^{2}$.

Tabela 3 - Capacidades dos reservatórios dimensionados pelos diferentes métodos para a cidade de Santos

\begin{tabular}{|c|c|c|c|c|c|c|c|c|c|c|c|}
\hline \multirow{2}{*}{ 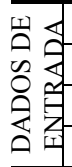 } & Demanda diária de água potável (litros) & 100 & 100 & 100 & 200 & 200 & 300 & 200 & 300 & 300 & \multirow{2}{*}{$\begin{array}{l}\text { Área de } \\
\text { captaçã } \\
o\left(\mathrm{~m}^{2}\right)\end{array}$} \\
\hline & \% substituição de água potável por pluvial & $30 \%$ & $40 \%$ & $50 \%$ & $30 \%$ & $40 \%$ & $30 \%$ & $50 \%$ & $40 \%$ & $50 \%$ & \\
\hline \multirow{17}{*}{ 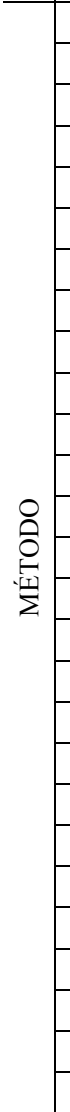 } & Método & \multicolumn{9}{|c|}{ Capacidade do reservatório (litros) } & \multirow{7}{*}{100} \\
\hline & Rippl & - & - & - & - & - & - & - & - & - & \\
\hline & Azevedo Neto & 42.526 & 42.526 & 42.526 & 42.526 & 42.526 & 42.526 & 42.526 & 42.526 & 42.526 & \\
\hline & Prático Alemão & 1.296 & 1.728 & 2.160 & 2.592 & 3.456 & 3.888 & 4.320 & 5.184 & 6.480 & \\
\hline & Prático Inglês & 16.875 & 16.875 & 16.875 & 16.875 & 16.875 & 16.875 & 16.875 & 16.875 & 16.875 & \\
\hline & Prático Australiano & - & - & - & - & - & - & - & - & - & \\
\hline & Netuno sem reservatório superior & 1.500 & 2.000 & 2.500 & 2.500 & 3.500 & 4.000 & 4.500 & 5.500 & 6.500 & \\
\hline & Simulação & - & - & - & - & - & - & - & - & - & \multirow{7}{*}{200} \\
\hline & Azevedo Neto & 85.051 & 85.051 & 85.051 & 85.051 & 85.051 & 85.051 & 85.051 & 85.051 & 85.051 & \\
\hline & Prático Alemão & 1.296 & 1.728 & 2.160 & 2.592 & 3.456 & 3.888 & 4.320 & 5.184 & 6.480 & \\
\hline & Prático Inglês & 33.750 & 33.750 & 33.750 & 33.750 & 33.750 & 33.750 & 33.750 & 33.750 & 33.750 & \\
\hline & Prático Australiano & - & - & - & - & - & - & - & - & - & \\
\hline & Netuno sem reservatório superior & 1.500 & 2.000 & 2.000 & 2.500 & 3.000 & 3.500 & 4.000 & 4.500 & 5.500 & \\
\hline & Netuno com reservatório superior & 1.000 & 1.500 & 2.000 & 2.500 & 3.000 & 3.500 & 4.000 & 4.500 & 5.500 & \\
\hline & Método & \multicolumn{9}{|c|}{ Capacidade do reservatório (litros) } & \multirow{3}{*}{300} \\
\hline & Rippl & - & - & - & - & - & - & - & - & - & \\
\hline & Netuno com reservatório superior & 1.000 & 1.500 & 2.000 & 2.500 & 3.000 & 3.500 & 3.500 & 4.500 & 5.500 & \\
\hline
\end{tabular}

56 Rupp, R. F.; Munarim, U.; Ghisi, E. 
Tabela 4 - Capacidades dos reservatórios dimensionados pelos diferentes métodos para a cidade de Palhoça

\begin{tabular}{|c|c|c|c|c|c|c|c|c|c|c|c|}
\hline \multirow{3}{*}{ 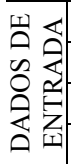 } & Demanda diária de água potável (litros) & 100 & 100 & 100 & 200 & 200 & 300 & 200 & 300 & 300 & \multirow{3}{*}{$\begin{array}{l}\text { Área de } \\
\text { captação } \\
\left(\mathrm{m}^{2}\right)\end{array}$} \\
\hline & Número de moradores & 2 & 2 & 2 & 2 & 2 & 2 & 2 & 2 & 2 & \\
\hline & \% substituição de água potável por pluvial & $30 \%$ & $40 \%$ & $50 \%$ & $30 \%$ & $40 \%$ & $30 \%$ & $50 \%$ & $40 \%$ & $50 \%$ & \\
\hline \multirow{17}{*}{ 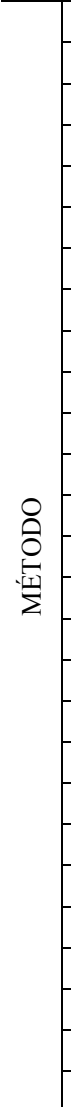 } & Método & \multicolumn{9}{|c|}{ Capacidade do reservatório (litros) } & \multirow{7}{*}{100} \\
\hline & Rippl & - & - & - & - & - & - & - & 523 & 3774 & \\
\hline & Azevedo Neto & 35.632 & 35.632 & 35.632 & 35.632 & 35.632 & 35.632 & 35.632 & 35.632 & 35.632 & \\
\hline & Prático Alemão & 1.296 & 1.728 & 2.160 & 2.592 & 3.456 & 3.888 & 4.320 & 5.184 & 6.480 & \\
\hline & Prático Inglês & 8.484 & 8.484 & 8.484 & 8.484 & 8.484 & 8.484 & 8.484 & 8.484 & 8.484 & \\
\hline & Prático Australiano & - & - & - & - & - & - & - & - & - & \\
\hline & Netuno sem reservatório superior & 2.000 & 2.500 & 3.000 & 4.000 & 5.500 & 6.500 & 7.000 & 8.000 & 1.0000 & \\
\hline & Simulação & - & - & - & - & - & - & - & - & - & \multirow{7}{*}{200} \\
\hline & Azevedo Neto & 71.264 & 71.264 & 71.264 & 71.264 & 71.264 & 71.264 & 71.264 & 71.264 & 71.264 & \\
\hline & Prático Alemão & 1.296 & 1.728 & 2.160 & 2.592 & 3.456 & 3.888 & 4.320 & 5.184 & 6.480 & \\
\hline & Prático Inglês & 16.968 & 16.968 & 16.968 & 16.968 & 16.968 & 16.968 & 16.968 & 16.968 & 16.968 & \\
\hline & Prático Australiano & - & - & - & - & - & - & - & - & - & \\
\hline & Netuno sem reservatório superior & 1.500 & 2.000 & 2.500 & 3.000 & 4.000 & 4.500 & 5.000 & 6.000 & 7.500 & \\
\hline & Netuno com reservatório superior & 1.500 & 2.000 & 2.500 & 3.000 & 3.500 & 4.500 & 5.000 & 6.000 & 7.500 & \\
\hline & Método & \multicolumn{9}{|c|}{ Capacidade do reservatório (litros) } & \multirow{3}{*}{300} \\
\hline & Rippl & - & - & - & - & - & - & - & - & - & \\
\hline & Netuno com reservatório superior & 1.500 & 1.500 & 2.000 & 2.500 & 3.500 & 4.000 & 4.500 & 5.500 & 7.000 & \\
\hline
\end{tabular}

Os resultados dos dimensionamentos dos reservatórios para a cidade de Santana do Ipanema estão representados na Tabela 5. Os dimensionamentos pelo método de Rippl não foram possíveis de se realizar para baixas demandas de água pluvial, para as áreas de captação de 200 e $300 \mathrm{~m}^{2}$. Já para os métodos da Simulação e Prático Australiano, não foi possível dimensionar os reservatórios para as demandas de água pluvial mais elevadas, para a área de captação de $100 \mathrm{~m}^{2}$, acontecendo o oposto para as áreas de captação de 200 e $300 \mathrm{~m}^{2}$, nas quais não foi possível dimensionar os reservatórios de água pluvial para as demandas mais baixas.

No caso do método de Rippl, não foi possível dimensionar os reservatórios porque não foi atendida a condição de que o volume de água pluvial deve ser superior à demanda de água pluvial. Já na aplicação dos métodos da Simulação e Prático Australiano, não foi possível dimensionar os reservatórios porque qualquer volume de reservatório escolhido era suficiente para garantir água pluvial durante os 12 meses do ano.

Os resultados obtidos pelos métodos de Azevedo Neto e Prático Inglês mostram-se exagerados em comparação aos dos outros métodos e variam apenas em função da área de captação. O método Prático Alemão varia em função da demanda de água pluvial, mas não em função da área de captação. No entanto, apresenta resultados semelhantes aos do Netuno. A mesma tendência é observada nas Tabelas 4 e 5 , que mostram os resultados para Palhoça e Santana do Ipanema respectivamente. 
Tabela 5 - Capacidades dos reservatórios dimensionados pelos diferentes métodos para a cidade de Santana do Ipanema

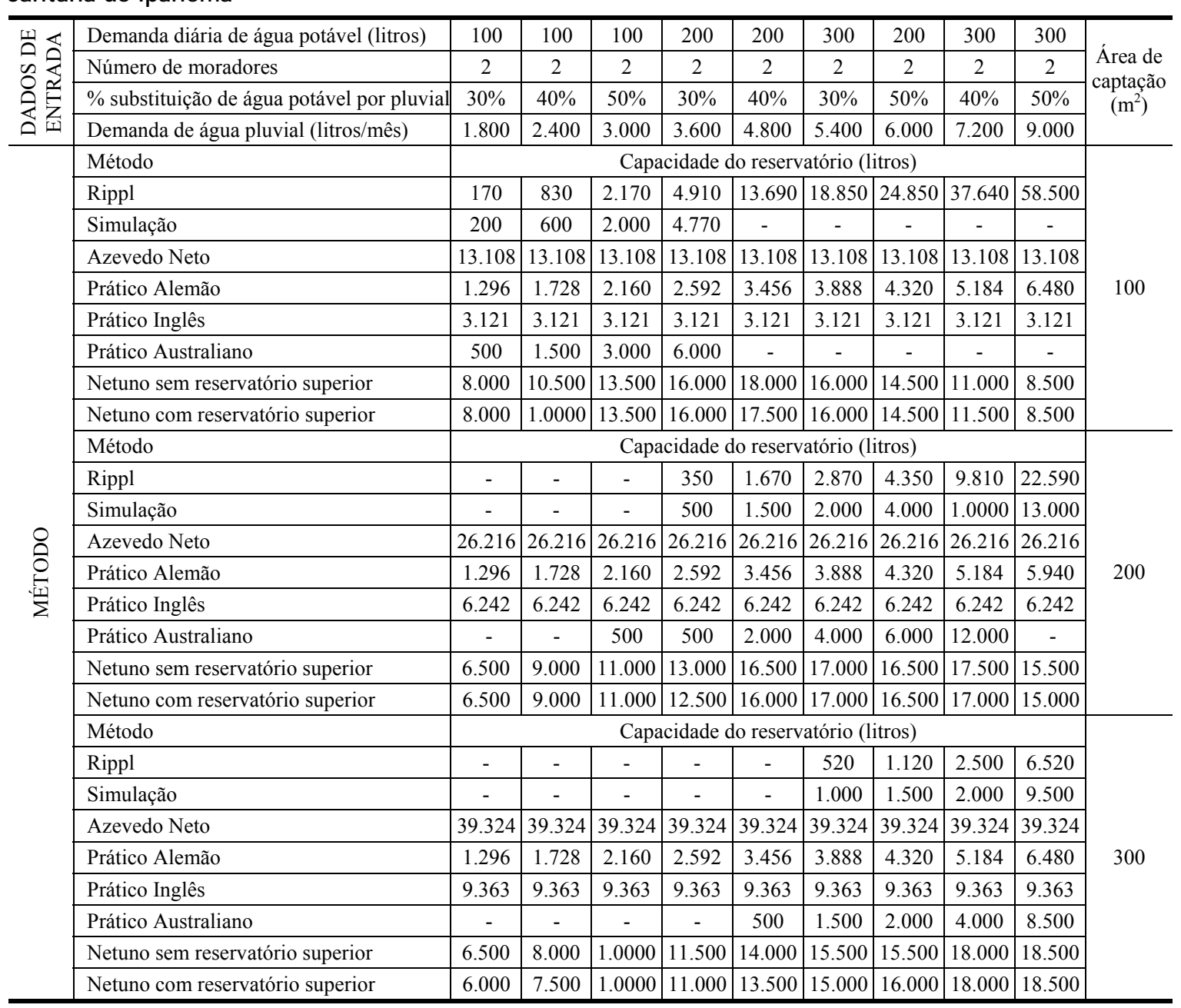

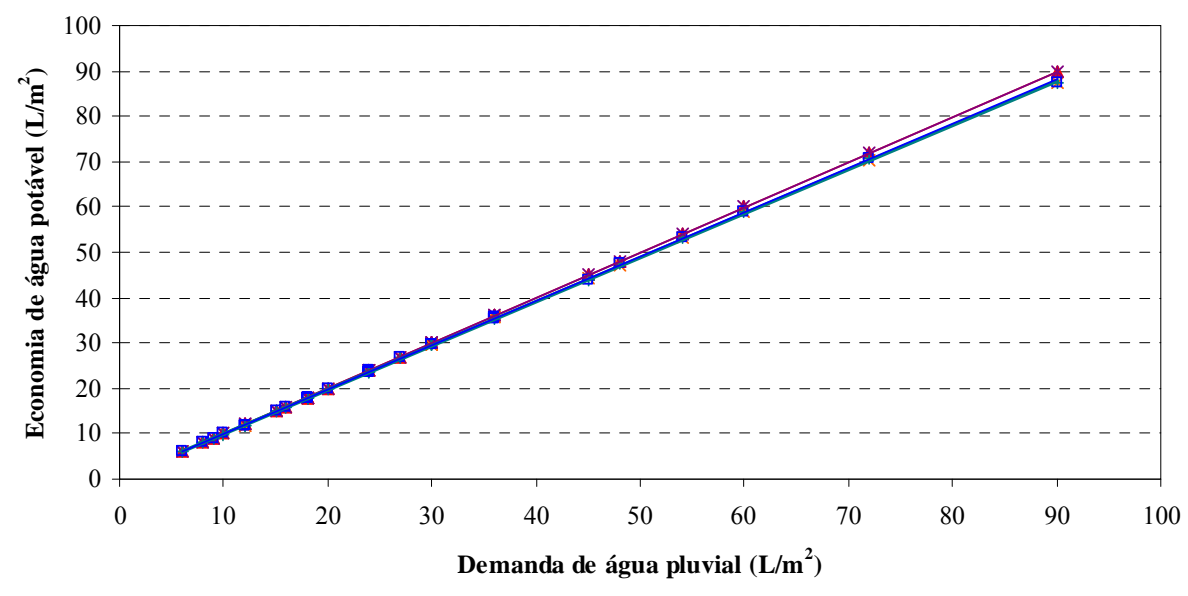

$\multimap$ Azeveto Neto $\multimap$ Prático Alemão $\rightarrow$ Prático Inglês $\longrightarrow$ Netuno sem RS $\multimap$ Netuno com RS

Figura 4 - Potencial de economia de água potável em função da demanda de água pluvial para a cidade de Santos 
A Figura 4 apresenta os resultados de potencial de economia pelos métodos de Azevedo Neto, Prático Alemão, Prático Inglês, Netuno sem reservatório superior, Netuno com reservatório superior de água potável, para a cidade de Santos, por unidade de área de captação. Como os métodos elencados na NBR 15527 (ABNT, 2007) não possibilitam o cálculo do potencial de economia de água potável, ele foi realizado no programa Netuno, a partir dos volumes de reservatórios calculados em cada um dos métodos que foram inseridos no Netuno como dados de entrada.

Como se pode perceber pela Figura 4, os potenciais de economia, entre os métodos aplicados a Santos, foram similares. A mesma tendência foi observada para a cidade de Palhoça, conforme mostra a Figura 5, com a exceção dos métodos de Rippl, da Simulação e Prático Australiano, que, de modo geral, apresentaram potenciais de economia inferiores aos demais métodos.

Já para Santana do Ipanema, conforme a Figura 6, de modo geral, pode-se perceber que os potenciais de economia foram inferiores às demandas de água pluvial. As diferenças de potenciais de economia entre os métodos, quando existentes, não são tão marcantes como as observadas para as cidades de Santos e Palhoça.

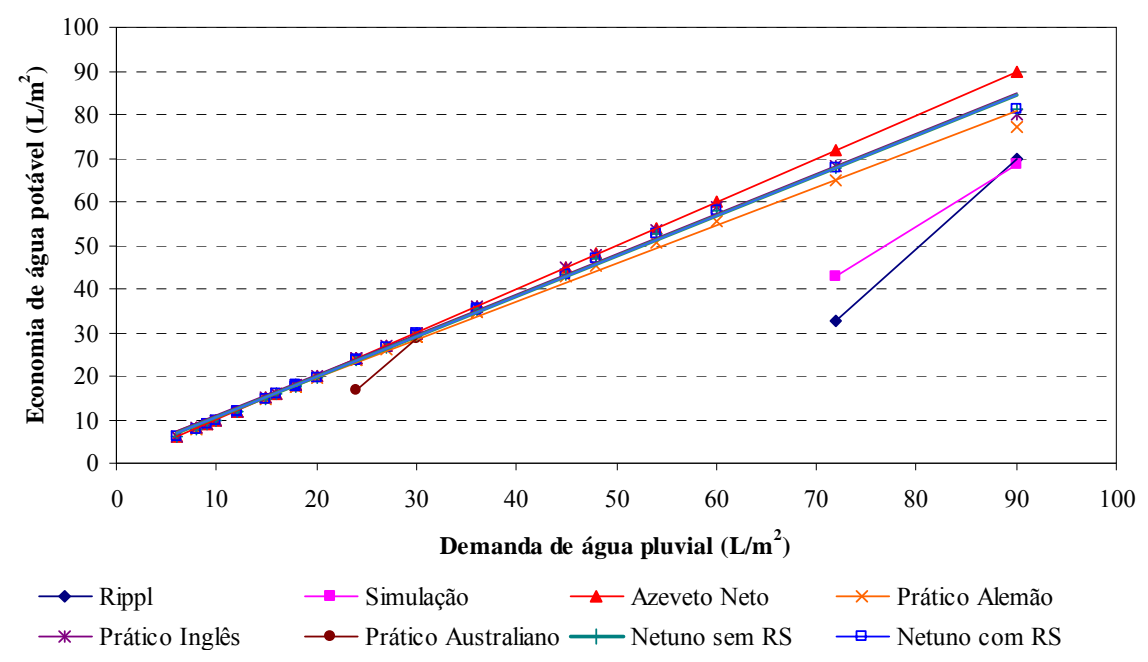

Figura 5 - Potencial de economia de água potável em função da demanda de água pluvial para a cidade de Palhoça

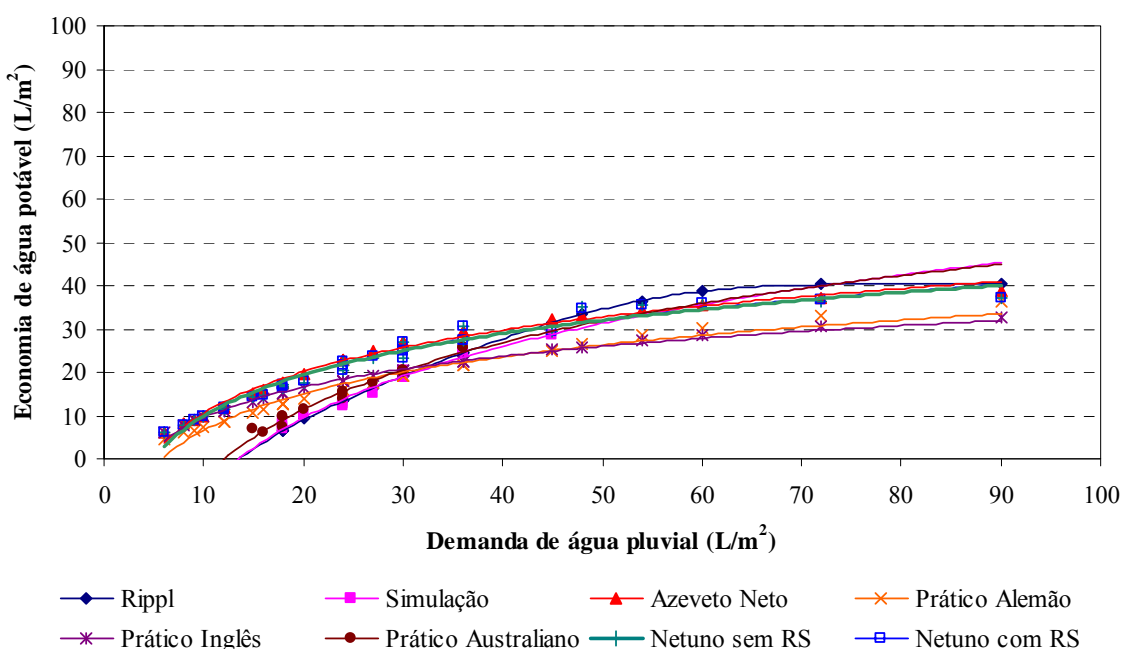

Figura 6 - Potencial de economia de água potável em função da demanda de água pluvial para a cidade de Santana do Ipanema 
Da análise das Tabelas 3 a 5 e das Figuras 4 a 6 , que apresentam as capacidades dos reservatórios e os potenciais de economia que eles gerariam, pode-se traçar alguns comentários.

Para a cidade de Santos, por apresentar alta precipitação pluviométrica, em todos os métodos em que foi possível dimensionar os reservatórios de água pluvial, os potenciais de economia de água potável ficaram muito próximos aos valores de demanda de água pluvial, como pode ser visualizado na Figura 4. Portanto, toda a demanda de água pluvial é atendida, mesmo com as menores capacidades de reservatório obtidas.

Para a cidade de Palhoça, que apresenta média precipitação pluviométrica, a mesma tendência foi observada, com as exceções do método de Rippl, do método da Simulação e do método Prático Australiano - como demonstrado na Figura 5 -, que conduziram a potenciais de economia inferiores aos valores de demanda de água pluvial.

Como os dimensionamentos oriundos do Netuno e do método Prático Alemão foram os que levaram a um menor volume de reservatório, não se justificam os superdimensionamentos provenientes dos demais métodos.

Porém, esse fato não aconteceu para o caso de Santana do Ipanema, cidade com baixa precipitação pluviométrica, conforme pode ser visualizado na Figura 6. Para essa cidade, somente os dimensionamentos realizados via Netuno se justificaram, e o método Prático Alemão não apresentou resultados satisfatórios de potencial de economia de água.

Dessa forma, pode-se afirmar que o algoritmo do Netuno otimiza o dimensionamento dos reservatórios de água pluvial por se basear no potencial de economia de água potável, funcionando satisfatoriamente nas três cidades analisadas: alta, média e baixa precipitação pluviométrica.

Os resultados dos dimensionamentos pelo Netuno, com e sem reservatório superior, foram praticamente iguais, diferindo ligeiramente em alguns casos. Isso se deve ao pequeno volume do reservatório superior simulado (310 litros), escolhido para atender à demanda diária máxima de água potável.

\section{Discussão sobre os métodos}

O método de Rippl possibilita dimensionar os reservatórios de água pluvial somente quando há diferença positiva entre o volume e a demanda de água pluvial, ou seja, quando em algum momento do período analisado a demanda supera o volume. Dessa forma, foi possível dimensionar os reservatórios de água pluvial para uma boa parte dos casos da cidade de Santana do Ipanema, porém para poucos casos da cidade de Palhoça e para nenhum caso da cidade de Santos. Fato similar ocorre para o método da Simulação, porém com o agravante de que se deve considerar, além do volume de água pluvial, o volume do reservatório cheio no início da contagem do tempo. Assim, por esse método, reduziu-se o número de casos em que foi possível dimensionar os reservatórios para a cidade de Santana do Ipanema. Pelo método Prático Australiano somente foi possível dimensionar os reservatórios quando, em algum período, a demanda de água pluvial superou o volume mensal de água pluvial. Isso ocorreu em boa parte dos casos da cidade de Santana do Ipanema, em poucos casos da cidade de Palhoça e em nenhum caso da cidade de Santos.

Por meio da aplicação desses métodos (Rippl, Simulação e Prático Alemão), observou-se que os volumes dos reservatórios aumentam à medida que aumenta a demanda de água pluvial. Em geral, o método de Rippl superdimensionou os volumes dos reservatórios.

Pelo método Azevedo Neto foi possível estimar o volume dos reservatórios de água pluvial em todos os casos simulados e para todas as cidades. Isso se deve ao fato de que suas equações exigem somente os valores de precipitação média anual, número de meses com pouca chuva ou seca e área de captação em projeção. Da mesma forma, utilizando o método Prático Alemão foi possível dimensionar os reservatórios para todos os casos e para todas as cidades, pois somente são necessários os valores do volume de água pluvial anual e da demanda anual de água pluvial. No caso do método Prático Inglês, são necessários somente os valores de precipitação média anual e da área de captação em projeção, sendo possível dimensionar os reservatórios em todos os casos simulados e para todas as cidades.

Os dimensionamentos pelos métodos Azevedo Neto e Prático Inglês resultaram em tamanhos de reservatório constantes para cada cidade, independentemente da demanda de água pluvial. Assim, quanto mais alta for a precipitação da cidade, maior será o volume do reservatório.

Quando analisados os volumes de reservatório em função dos potenciais de economia estimados pelo Netuno, para Santana do Ipanema com áreas de captação de 100 e $200 \mathrm{~m}^{2}$, o método de Rippl superdimensionou os reservatórios, e os potenciais de economia foram inferiores aos apresentados pelo Netuno. Já para área de captação de $300 \mathrm{~m}^{2} \mathrm{e}$ para os casos dimensionados de Palhoça, o método de Rippl subdimensionou os reservatórios, 
apresentando potenciais de economia inferiores aos do Netuno.

Os métodos da Simulação e Prático Australiano subdimensionaram os reservatórios, e os potenciais de economia obtidos foram inferiores aos do Netuno. O mesmo ocorreu nas simulações para a cidade de Santana do Ipanema quando se utilizou o método Prático Alemão.

Entretanto, para as cidades de Santos e Palhoça, os dimensionamentos dos reservatórios pelo método Prático Alemão foram similares aos dimensionados pelo Netuno. Logo, os potenciais de economia também foram semelhantes.

Os métodos Prático Inglês e Azevedo Neto também garantiram potenciais de economia similares aos obtidos pelo Netuno quando em condições de alta e média precipitação (Santos e Palhoça). No entanto, os reservatórios são superdimensionados nessas situações. Já na cidade com baixa precipitação (Santana do Ipanema), os reservatórios foram subdimensionados pelo método Prático Inglês, resultando em potenciais de economia inferiores aos apresentados pelo Netuno. Nas simulações pelo método Azevedo Neto, ocorreram algumas exceções para Santana do Ipanema, nos casos com área de captação de 100 $\mathrm{m}^{2}$, em que alguns dos volumes de reservatório foram da mesma ordem de grandeza dos dimensionados pelo Netuno.

Como o dimensionamento no Netuno é realizado levando-se em consideração o potencial de economia de água potável, os volumes de reservatório aumentam com a demanda de água pluvial até ser definido o volume ideal (que é baseado na definição dada pelo usuário no momento da simulação). Essa tendência pode ser constatada pelas Figuras 7 e 8, que apresentam os resultados de potencial de economia em função do volume de reservatório para as cidades de Santos e Palhoça respectivamente, com área de captação de $100 \mathrm{~m}^{2}$, demanda de água potável de 300 litros por pessoa/dia e porcentagens de substituição de água potável por pluvial de $30 \%, 40 \%$ e $50 \%$. Para Santos, as capacidades dos reservatórios foram de 4.000, 5.500 e 6.500 litros, e para Palhoça, de $6.500,8.000$ e 10.000 litros.

Porém, para o caso de Santana do Ipanema, os volumes de reservatório nem sempre aumentaram com a demanda de água pluvial, fato este explicado por essa cidade apresentar uma baixa precipitação pluviométrica; com o aumento da demanda de água pluvial, o acréscimo do potencial de economia de água (que seria pequeno) não justificaria o aumento do reservatório. Desse modo, as simulações no Netuno, em alguns casos, resultaram em volumes ideais inferiores com o aumento da demanda de água pluvial. A Figura 9 apresenta essa constatação para Santana do Ipanema, com área de captação de $100 \mathrm{~m}^{2}$, demanda de água potável de 300 litros por pessoa/dia e porcentagens de substituição de água potável por pluvial de $30 \%, 40 \%$ e $50 \%$, que conduziram a capacidades de reservatório de 16.000, 11.000 e 8.500 litros respectivamente.

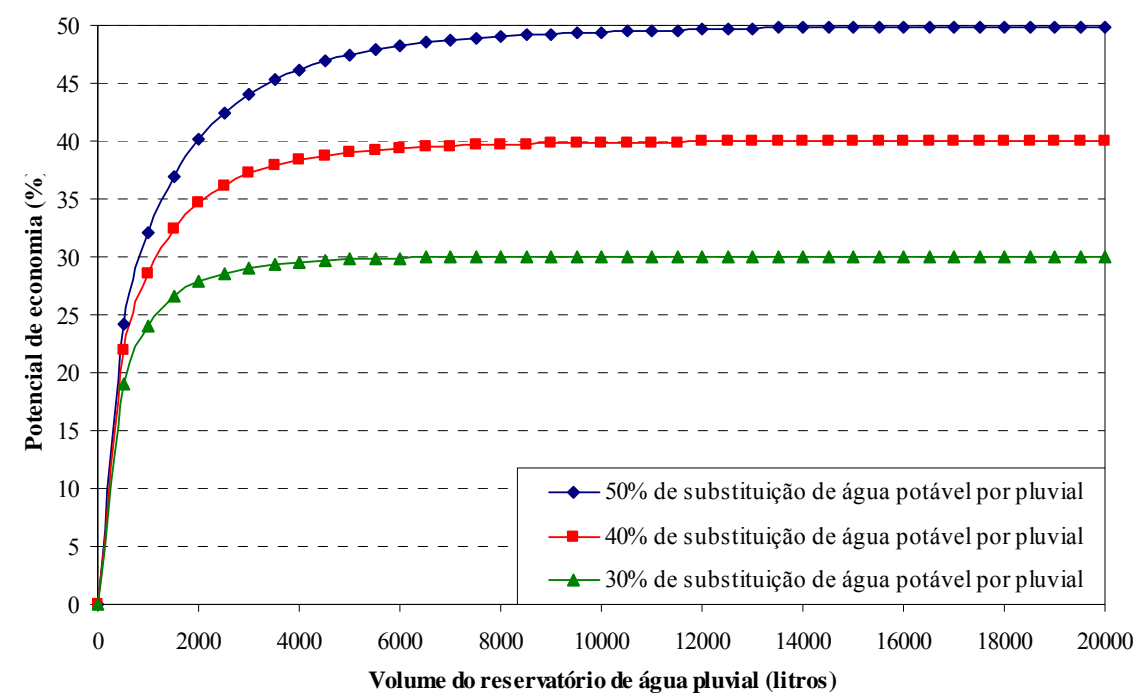

Figura 7 - Potencial de economia de água potável em função do volume do reservatório inferior para a cidade de Santos

Nota: área de captação de $100 \mathrm{~m}^{2}$, demanda de água potável de 300 litros por pessoa/ dia. 


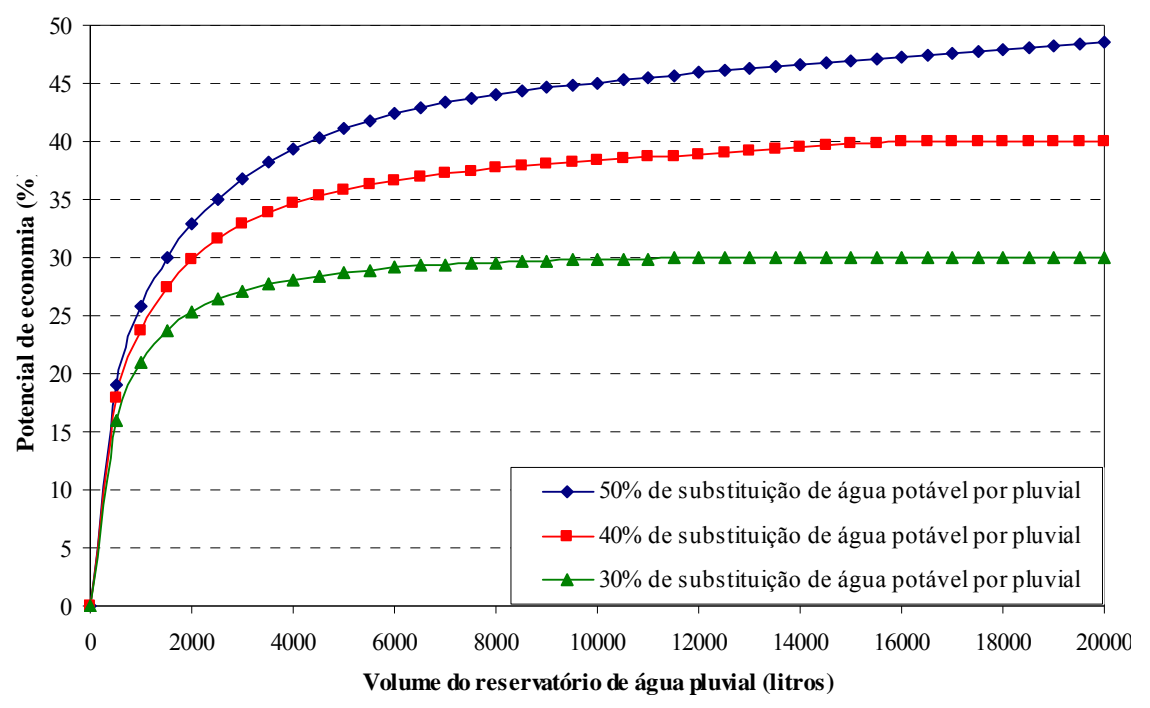

Figura 8 - Potencial de economia de água potável em função do volume do reservatório inferior para a cidade de Palhoça

Nota: área de captação de $100 \mathrm{~m}^{2}$, demanda de água potável de 300 litros por pessoa/ dia.

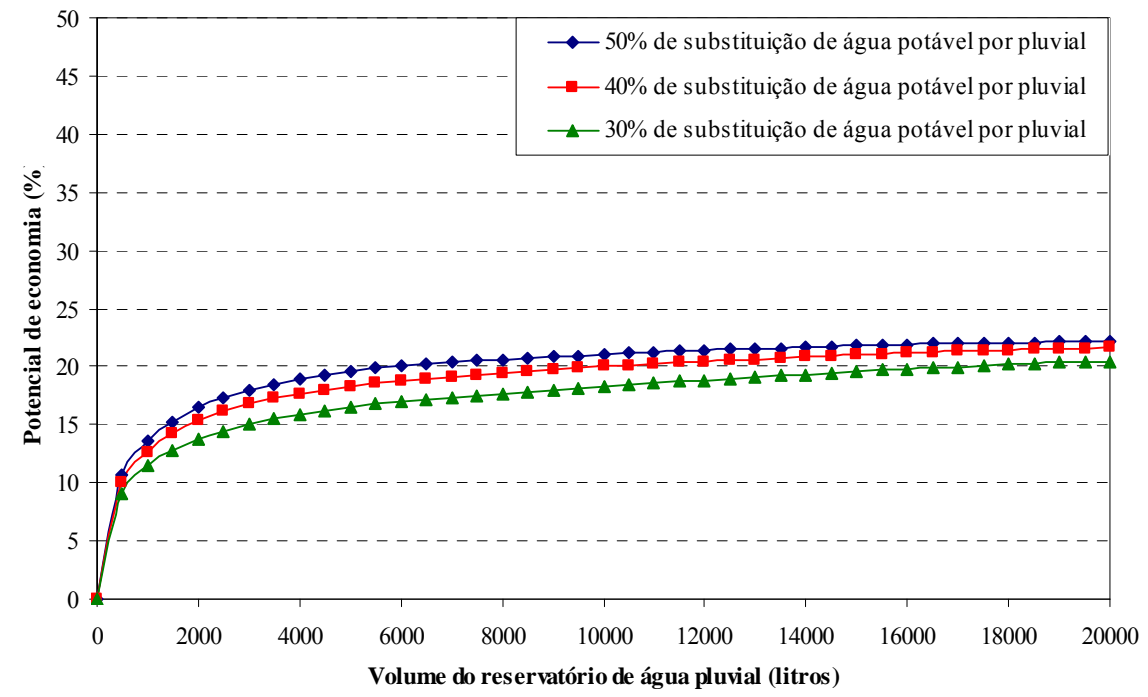

Figura 9 - Potencial de economia de água potável em função do volume do reservatório inferior para a cidade de Santana do Ipanema

Nota: área de captação de $100 \mathrm{~m}^{2}$, demanda de água potável de 300 litros por pessoa/ dia.

Neste trabalho, o volume ideal do reservatório no Netuno foi definido como aquele em que o potencial de economia de água potável aumentasse $0,5 \%$ ou menos, quando houvesse o aumento do volume do reservatório em 500 litros. Essa porcentagem mostrou-se adequada para as cidades de Santos e Palhoça - Figuras 7 e 8 respectivamente. Porém, como se pode perceber pela Figura 9 (Santana do Ipanema), os potenciais de economia não aumentaram consideravelmente a partir de certo volume de reservatório. Desse modo, a decisão pelo volume ideal do reservatório poderia ser feita de modo visual, ou através de um aumento do valor de $0,5 \%$.

\section{Conclusões}

De maneira geral, pode-se concluir que os métodos apresentados na NBR 15527 (ABNT, 2007) mostram-se insuficientes e inadequados no atendimento pleno dos quesitos analisados neste artigo, quais sejam:

(a) aplicabilidade do método aos casos avaliados; dimensionamento do reservatório; e

(b) cálculo do potencial de economia de água potável.

Utilizando-se os métodos de Rippl, da Simulação e Prático Australiano, somente foi possível 
dimensionar os reservatórios nos casos em que, durante o período considerado, a demanda de água pluvial supera seu volume mensal captado. O dimensionamento através do método de Azevedo Neto, do método Prático Alemão e do método Prático Inglês foi possível em todos os casos simulados.

Nos métodos de Rippl, da Simulação, Prático Alemão e Prático Australiano, os volumes de reservatório resultantes aumentam com a demanda de água pluvial. Ou seja, aumentando-se a demanda, a capacidade necessária no reservatório também será maior, sem necessariamente implicar um maior potencial de economia de água potável. Nos dimensionamentos pelos métodos Azevedo Neto e Prático Inglês, os volumes dos reservatórios foram sempre constantes, independentemente da demanda de água pluvial, variando apenas em função da precipitação.

Nenhum dos métodos fornece o potencial de economia de água potável em função do volume do reservatório de água pluvial, à exceção do Netuno, que foi então utilizado para calcular o potencial de economia dos reservatórios obtidos por cada um dos outros métodos. O Netuno também foi o único cujo dimensionamento sempre se ajustou em função da demanda de água pluvial e do regime de precipitação.

Quando comparados os volumes de reservatório dimensionados em cada método com o melhor volume em termos do potencial de economia de água potável, constatou-se que os métodos de Rippl, Simulação e Azevedo Neto resultam em reservatórios maiores do que o ideal. No entanto, não há aumento no potencial de economia de água potável. Os volumes de reservatório obtidos pelo método Prático Inglês foram superdimensionados nos casos em que a precipitação é alta, e subdimensionados quando a precipitação é baixa. $\mathrm{Na}$ situação de baixa precipitação, o método Prático Alemão também subdimensiona os reservatórios. Nos casos em que foi possível utilizar o método Prático Australiano, os reservatórios também foram subdimensionados. No caso do Netuno, o usuário pode escolher a capacidade de reservatório de água pluvial em função do respectivo potencial de economia de água potável, já que esse é um dado de saída do programa.

\section{Referências}

AMORIM, S. V.; PEREIRA, D. J. A. Estudo Comparativo dos Métodos de Dimensionamento para Reservatórios Utilizados em Aproveitamento de Água Pluvial. Ambiente Construído, Porto Alegre, v. 8, n. 2, p. 53-66, 2008 a.
AMORIM, S. V.; PEREIRA, D. J. A. Estudo Comparativo dos Métodos de Dimensionamento para Reservatórios Utilizados em Aaproveitamento de Água Pluvial. In: ENCONTRO NACIONAL DE TECNOLOGIA DO AMBIENTE CONSTRUÍDO, 12., Fortaleza, 2008. Anais... Fortaleza: Antac, 2008b.

APPAN, A. A Dual-Mode System for Harnessing Roofwater for Non-Potable Uses. Urban Water, v. 1, p. 317-321, 1999.

\section{ASSOCIAÇÃO BRASILEIRA DE NORMAS}

TÉCNICAS. NBR 15527: aproveitamento de água de chuva de coberturas em áreas urbanas para fins não potáveis. Rio de Janeiro, 2007.

BASINGER, M.; MONTALTO, F.; LALL, U. A Rainwater Harvesting System Reliability Model Based on Nonparametric Stochastic Rainfall Generator. Journal of Hydrology, v. 392, n. 3/4, p. 105-118, out. 2010.

BEZERRA, S. M. C. et al. Dimensionamento de Reservatório para Aproveitamento de Água de Chuva: comparação entre métodos da ABNT NBR 15527:2007 e Decreto Municipal 293/2006 de Curitiba, PR. Ambiente Construído, Porto Alegre, v. 10, n. 4, p. 219-231, out./dez. 2010.

CARVALHO, G. S.; OLIVEIRA, S. C.; MORUZZI, R. B. Cálculo do Volume do Reservatório de Sistemas de Aproveitamento de Água de Chuva: comparação entre métodos para aplicação em residência unifamiliar. In: SIMPÓSIO NACIONAL DE SISTEMAS PREDIAIS, 10., São Carlos, 2007. Anais... São Carlos, 2007.

EROKSUZ, E.; RAHMAN, A. Rainwater Tanks in Multi-Unit Buildings: a case study for three Australian cities. Resources, Conservation and Recycling, v. 54, n. 12, p. 1449-1452, 2010.

FEWKES, A. The Use of Rainwater for WC Flushing: the Field Testing of a Collection System. Building and Environment, v. 34, n. 6, p. 765772, nov. 1999.

GHISI, E. Parameters Influencing the Sizing of Rainwater Tanks for Use in Houses. Water

Resources Management, v. 24, n. 10, p. 23812403, 2010.

GHISI, E.; BRESSAN, D. L.; MARTINI, M. Rainwater Tank Capacity and Potential for Potable Water Savings by Using Rainwater in the Residential Sector of Southeastern Brazil. Building and Environment, v. 42, n. 1, p. 16541666, 2007. 
GHISI, E.; CORDOVA, M. M.; ROCHA, V. L. Netuno 3.0: aproveitamento de água pluvial. Programa computacional. 2009.Disponível em: <www.labeee.ufsc.br>. Acesso em: 23 out. 2011.

GHISI, E.; FERREIRA, D. F. Potential for Potable Water Savings by Using Rainwater and Greywater in a Multi-Storey Residential Building in Southern Brazil. Building and Environment, v. 42, n. 7, p. 2512-2522, 2007.

HEINE, C. A. et al. Monitoramento da Depleção e Detecção dos Limites de Exploração do Sistema Aqüífero Guarani em Ivoti (RS): uma aplicação de geoprocessamento no gerenciamento municipal do uso sustentável de recursos hídricos subterrâneos. GÆA, v. 1, n.1, p. 24-33, 2005.

HELMREICH, B.; HORN, H. Opportunities in Rainwater Harvesting. Desalination, v. 248, n. 1/2, p. 118-124, 2009.

KHASTAGIR, A.; JAYASURIYA, N. Optimal Sizing of Rain Water Tanks for Domestic Water Conservation. Journal of Hydrology, v. 381, n. 3/4, p. 181-188, 2010.

MIERZWA, J. C. et al. Águas Pluviais: método de cálculo do reservatório e conceitos para um aproveitamento adequado. Rega, v. 4, n. 1, p. 2937, 2007.
OLIVEIRA, S. M.; GHISI, E. Potential for Potable Water Savings by Combining the Use of Rainwater and Greywater in Houses in Southern Brazil. Building and Environment, v. 42, n. 4, p. 1731-1742, 2007.

ROCHA, V. L. Validação do Algoritmo do Programa Netuno para Avaliação do Potencial de Economia de Água Potável e Dimensionamento de Reservatórios de Sistemas de Aproveitamento de Água Pluvial em Edificações. 166 f. Florianópolis, 2009. Dissertação (Mestrado em Engenharia Civil) Curso de Pós-Graduação em Engenharia Civil, Universidade Federal de Santa Catarina, Florianópolis, 2009.

THOMAZ, P. Aproveitamento de Água Pluvial. São Paulo: Navegar, 2003.

UNITED NATIONS ENVIRONMENT

PROGRAMME. Global Environment Outlook 3: past, present and future perspectives. Earthscan, UK, 2002.

VILLARREAL, E. L.; DIXON, A. Analysis of a Rainwater Collection System for Domestic Water Supply in Ringdansen, Norrköping, Sweden.

Building and Environment, v. 40, n. 9, p. 11741184 , set. 2005.

ZHANG, Y. et al. Potential for Rainwater Use in High-Rise Buildings in Australian Cities. Journal of Environmental Management, v. 91, n. 1, p. 222-226, 2009.

Revista Ambiente Construído

Associação Nacional de Tecnologia do Ambiente Construído

Av. Osvaldo Aranha, 99 - 3o andar, Centro Porto Alegre - RS - Brasil CEP $90035-190$

Telefone: +55 (51) 3308-4084 Fax: +55 (51) 3308-4054

www. seer. ufrgs. br/ ambienteconstruido

E-mail: ambienteconstruido@ufrgs.br

64 Rupp, R. F.; Munarim, U.; Ghisi, E. 